\title{
Extraesophageal Reflux and Upper Aerodigestive Tract Diseases
}

\author{
Peter Jecker ${ }^{a}$ Lisa A. Orloff ${ }^{b}$ Wolf J. Mann ${ }^{a}$ \\ ${ }^{a}$ Department of Otolaryngology, Mainz Medical School, Mainz, Germany; ${ }^{b}$ Division of Otolaryngology/Head and \\ Neck Surgery, University of California, San Diego, Calif., USA
}

\section{Key Words}

Extraesophageal reflux $\cdot$ Head and neck diseases · Gastroesophageal reflux $\cdot \mathrm{pH}$ monitoring $\cdot$ Reflux therapy

\begin{abstract}
Reflux disease can cause multiple disorders not only of the esophagus but also of the upper aerodigestive tract. In the last decade, an association between reflux disease and multiple head and neck diseases was described, including those of the larynx and pharynx as well as those of the nose, the sinuses and the middle ear. The present article summarizes these different diseases and possible pathomechanisms are explained. In particular, there is a need to differentiate between the classical gastroesophageal reflux disease (GERD) and the extraesophageal manifestation of the reflux disease, called extraesophageal reflux (EER). Both diseases are characterized by different symptoms and can cause different disorders. To differentiate between GERD and EER, double-probe $\mathrm{pH}$ monitoring is mandatory. At last, some aspects of reflux therapy are explained.
\end{abstract}

Copyright $(2005$ S. Karger AG, Basel

\section{Gastroesophageal vs. Extraesophageal Reflux Disease}

During the last decade, there has been increasing interest in and awareness of diseases caused by retrograde reflux of acidic fluid from the stomach into the esophagus and even into the laryngopharynx. Reflux of gastric contents such as acid and pepsin can cause disorders of subsites in the upper aerodigestive tract including the larynx, the pharynx, the trachea, the lung, the paranasal sinuses and the middle ear (table 1). The public health impact of these diseases is reflected in earlier studies, where the number of people suffering from gastroesophageal reflux disease (GERD) in the United States has been estimated to be 75 million. Within this population, $50 \%$ of individuals also show signs of extraesophageal reflux (EER) [1].

EER is distinguishable from GERD in several ways. Whereas classic symptoms of GERD include heartburn, regurgitation and dyspepsia, symptoms of EER tend to be less specific and include frequent throat clearing, globus or foreign body sensation, cough or hoarseness [2-4]. Patients suffering from GERD are known to have an increased risk of developing esophageal cancer, while EER is associated with diseases and possibly with cancers of the larynx and the lungs as well as disorders of the paranasal sinuses and the middle ears. Finally, GERD and EER can have different diurnal patterns and relationships to upright versus supine positioning.

Peter Jecker, MD, PhD

Department of Otolaryngology

Mainz Medical School, Langenbeckstrasse 1

DE-55101 Mainz (Germany)

Tel. +49 613117 7361, Fax +496131176637, E-Mail jecker@hno.klinik.uni-mainz.de

\begin{tabular}{ll}
\hline KARGER & ( 2005 S. Karger AG, Basel \\
Fax +4161306 12 34 & 0301-1569/05/0674-0185\$22.00/0 \\
$\begin{array}{l}\text { E-Mail karger@karger.ch } \\
\text { www.karger.com }\end{array}$ & $\begin{array}{l}\text { Accessible online at: } \\
\text { www.karger.com/orl }\end{array}$
\end{tabular}


Table 1. Diseases and unspecific symptoms which are suspected to be associated with EER

\begin{tabular}{ll}
\hline Location & Disease/symptom \\
\hline Larynx, trachea & Laryngitis posterior \\
and lung & Laryngospasm \\
& Subglottic and tracheal stenosis \\
& Leukoplakia \\
& Laryngeal cancer \\
& Functional dysphonia/hoarseness \\
& Vocal cord nodules \\
& Larynx granuloma \\
& Tracheal stenosis \\
& Asthma \\
& Chronic cough \\
& Chronic bronchitis \\
& Lung fibrosis \\
& Globus sensation \\
& Chronic pharyngitis \\
& Dysphagia \\
& Burning tongue \\
Zenker diverticulum & OSAS \\
Pharynx & Frequent throat clearing (throat irritation) \\
& Vasomotoric rhinitis \\
& Chronic sinusitis \\
\hline Ear & Chronic otitis media \\
& Glue ear \\
\hline Nose & \\
\hline & \\
& \\
& \\
&
\end{tabular}

Clinical findings in GERD differ from those in EER. In patients with GERD, esophagitis can typically be detected by endoscopy. Patients with EER, on the other hand, often have edema and erythema of the arytenoid and interarytenoid mucosa, or laryngitis. The most objective means by which EER can currently be documented is $\mathrm{pH}$ monitoring in the hypopharynx, proximal to the upper esophageal sphincter(UES). Selective $\mathrm{pH}$ monitoring in the distal esophagus does not produce reliable results concerning EER, so monitoring is ideally performed over $24 \mathrm{~h}$ using two probes, one proximal to the UES and the other proximal to the lower esophageal sphincter (LES). Histologic differences between the esophageal mucosa and the mucosa of the larynx and pharynx confer different intrinsic resistance to peptic injuries. Even when the laryngeal mucosa shows signs of EER, the esophageal mucosa may be uninjured [4]. Postma [5] has described how a majority of patients with voice disorders who suffered from EER did not have GERD. Similarly, Little [6] has found that about half of the children with document- ed EER have normal acid exposure times in the esophagus. Koufman et al. [2] noted that fewer than $20 \%$ of patients with EER $(n=59)$ suffered from esophagitis, diagnosed by esophagoscopy and histology. In contrast, Yelon and Goldberg [7] found esophageal abnormalities in $80 \%$ of patients with posterior laryngitis. By using a double-probe $\mathrm{pH}$ monitoring system, we found in our own patients that $1 / 3$ of those with normal esophageal acid exposure times, i.e. having a DeMeester score $\leq 14.72$, suffered from EER. Regardless of the differences in these studies, the common conclusion is that $\mathrm{pH}$ monitoring in the hypopharynx is essential to detect EER. Double-probe measurement of the $\mathrm{pH}$ enables accurate interpretation of hypopharyngeal data (fig. 1). Even though the proximal probe is inserted under visual control, there is a risk of its displacement which is followed by recording artifacts and drops in $\mathrm{pH}$. In order to assure the validity of the proximal measurements, every decrease in $\mathrm{pH}$ in the hypopharynx must be preceded by a $\mathrm{pH}$ decrease at the distal probe in the esophagus.

\section{Normal pH Values of Gastroesophageal and Extraesophageal Reflux Events}

Normal values for GERD have been well defined, but those for EER have been less well studied or agreed upon. The most widely used classification system for GERD is the DeMeester Index. This scoring system uses a pH of 4 as the threshold based on the observations of Tuttle, who in 1961 described pyrosis when acid $(\mathrm{pH}=4)$ is perfused in the distal esophagus [8]. In the hypopharynx, the threshold for a reflux event is also commonly defined as a $\mathrm{pH} \leq 4$. However, pepsin is active and thus injurious to the mucosa of the upper aerodigestive tract at a $\mathrm{pH}$ of up to 5. Thus, the use of the DeMeester Index may mistakenly exclude EER events that can cause mucosal injury. We are currently conducting a study to determine normal values for EER by collecting data on the number of reflux events at $\mathrm{pH} \leq 4$, as well as the number at $\mathrm{pH}$ $\leq 5$.

Another controversial normative value concerns the number of EER events in healthy individuals. A scoring system comparable to that of GERD (DeMeester score) does not exist for EER. According to Koufman, asymptomatic healthy persons have no EER events, whereas Toohill et al. showed that $20 \%$ of investigated healthy volunteers had EER events (summarized in Postma [5]). Smit [9] detected up to three reflux episodes in healthy persons $(n=20)$ at the level of the UES and de- 


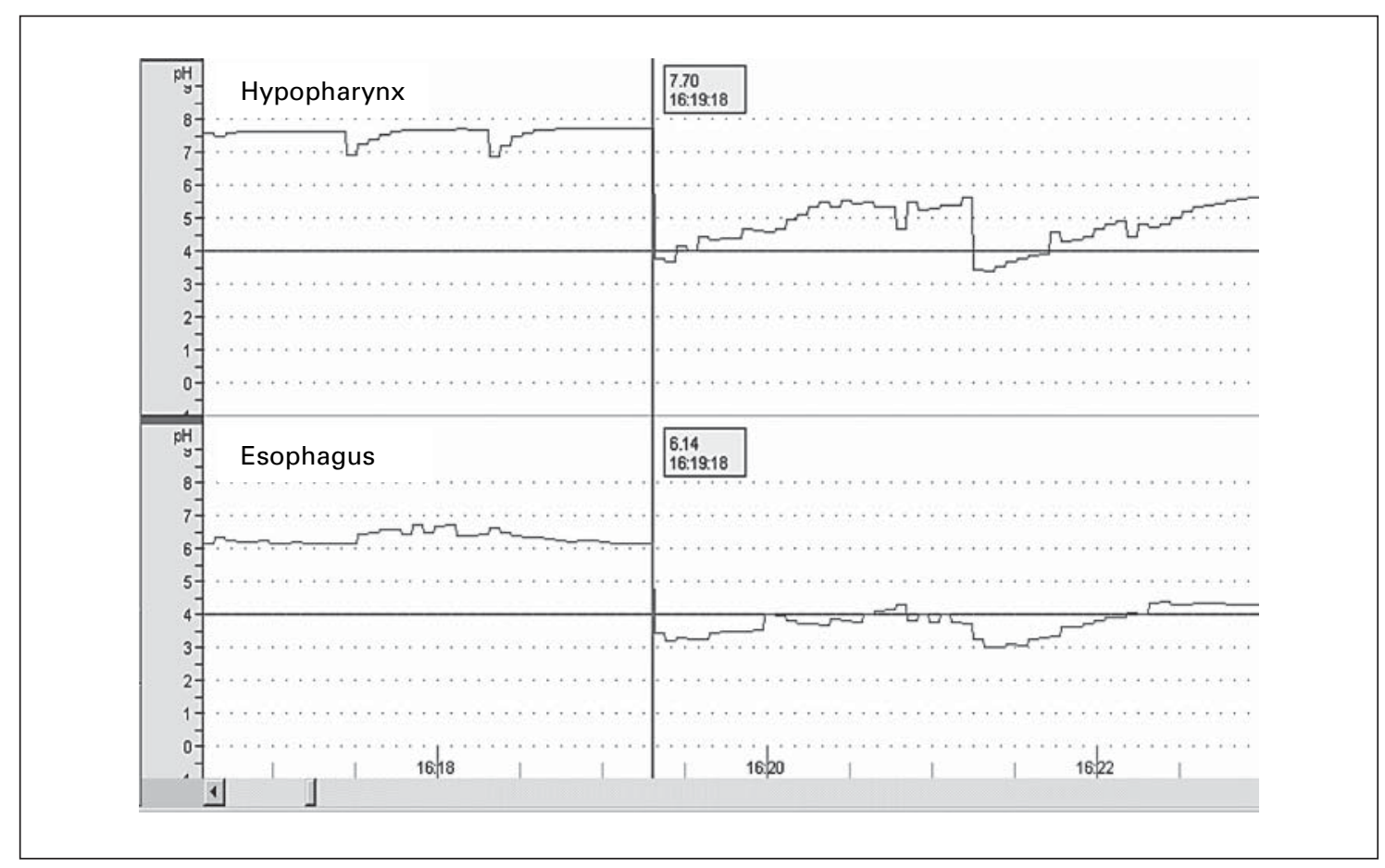

Fig. 1. An extract from the 24-hour double-probe $\mathrm{pH}$ monitoring: to avoid false-positive results, it is necessary to compare the hypopharyngeal $\mathrm{pH}$ with the esophageal $\mathrm{pH}$. An EER event must be preceded by a pH decrease at the distal probe in the esophagus.

scribed a mean reflux frequency of 1.8 in $24 \mathrm{~h}$. He further found a total time with a $\mathrm{pH} \leq 4$ of $0.01 \%(0.02 \%$ in upright position) in healthy subjects. Vincent et al. [10] also described physiological reflux at the level of the hypopharynx $($ median $=1$ reflux $/ 24 \mathrm{~h}, 95$ th percentile $=6.9$ events). Further complicating the definition of physiological reflux is the fact that there is variability in the positioning of the proximal probe, with some studies using a position proximal to the UES and others using a position just distal to the UES. Our own data support a normal range of 2-6 physiological hypopharyngeal reflux $(\mathrm{pH}$ $\leq 4)$ events in $24 \mathrm{~h}$ with the proximal probe positioned proximal to the UES.

For consistency, a hypopharyngeal reflux episode should occur directly after a reflux event is measured in the esophagus (distal probe). $\mathrm{pH}$ decline must not be a consequence of intake of food or beverage. Exclusion of postprandial events requires that the patients keep a dietary intake $\log$ that can subsequently be correlated with the 24-hour $\mathrm{pH}$ data.

\section{EER and Laryngeal Diseases}

The most studied target of EER has been the larynx. This may be attributed to the fact that the larynx is directly next to the esophagus and thus represents the first organ to be injured when gastric fluid refluxes beyond the esophagus. Laryngeal manifestations include inflammatory diseases, neoplasms and disorders of laryngeal function (table 1) in both adults and children.

Posterior laryngitis is the best-known manifestation of EER $[11,12]$. Many clinicians diagnose EER based on laryngoscopy alone, whereby thickening of interarytenoid mucosa and erythema and/or edema of the arytenoid mucosa can be seen. The addition of double-probe $\mathrm{pH}$ monitoring to the subjective laryngoscopic diagnosis of EER suggests that $70 \%$ of patients with posterior laryngitis have more objective $\mathrm{pH}$ evidence of EER [3]. Furthermore, the absence of posterior laryngitis by laryngoscopy does not exclude EER. Ylitalo et al. [13] have described normal laryngeal mucosal findings in patients with up to $15 \mathrm{pH}$-confirmed EER episodes. This group also attributed various benign lesions of the larynx, such as granu- 
lomata, ulcers and nodules to acid exposure and injury of the laryngeal mucosa. An association between EER and subglottic laryngotracheitis has also been observed [14]. Several studies have suggested that more than $50 \%$ of patients with such benign lesions suffer from EER [14$16]$.

It is well established that GERD increases the risk of esophageal adenocarcinoma and squamous cell carcinoma. Similarly, data support a higher incidence of laryngeal cancer in patients suffering from EER, apparently due to chronic inflammation. Glanz and Kleinsasser [17] suggested in 1976 that chronic inflammation can give rise to laryngeal cancer. Separate studies by Galli et al. [18] (esophageal 24-hour $\mathrm{pH}$ monitoring) and El-Serag et al. [19] (case control study) found an $80 \%$ incidence of GERD in patients with squamous cell carcinoma of the larynx and hypopharynx. Koufman and Burke [20] detected EER in $66 \%$ of patients $(33 / 50)$ with early glottic cancer by 24 -hour double-probe $\mathrm{pH}$ monitoring. These studies did not consider other lifestyle factors that can contribute both to reflux and to cancer development. A study using double-probe $\mathrm{pH}$ testing in patients with premalignant and malignant lesions of the hypopharynx and larynx who do not smoke or drink alcohol is warranted.

Finally, EER can also cause disorders of laryngeal function. Most patients with EER suffer from voice alterations. EER is also highly associated with paroxysmal laryngospasm [21]. Many patients with laryngospasm respond to antireflux therapy [22].

\section{EER, Chronic Cough, Asthma and Obstructive Sleep Apnea Syndrome}

EER may lead to mucosal injuries in the trachea, the bronchi and the lungs. Chronic cough and bronchitis are documented symptoms in $30-50 \%$ of patients suffering from GERD [23]. Harding et al. [24] noted improvement in asthma symptoms and/or peak expiratory flow rate by more than $20 \%$ in patients treated with a proton pump inhibitor (PPI), and pulmonary function improved in $75 \%$ of such patients overall. The pathophysiology of reflux-induced pulmonary diseases is poorly understood. Whether the refluxate actually enters the trachea, the bronchi and the lungs with the result of direct acid and pepsin mucosal contact is not clear. These pulmonary symptoms may be induced via a neural mechanism, mediated by a vagal reflex which is triggered by contact of the esophageal mucosa with the refluxate. Such a neural pathway might explain why patients whose laryngoscopy is inconspicuous still respond to antireflux treatment. Double-probe $\mathrm{pH}$ monitoring would help to differentiate between GERD and EER in these patients and would lead to a better understanding of the mechanisms.

A similar correlation exists between reflux disease and obstructive sleep apnea syndrome (OSAS). Both EER and OSAS are being increasingly diagnosed. Valipour et al. [25] observed that symptomatic GERD is common in patients with sleep-disordered breathing, but noted no difference between patients with OSAS and those with snoring alone. Ing et al. [26] performed simultaneous polysomnography and single-probe $\mathrm{pH}$ monitoring (esophagus only) and were able to show that patients with OSAS had 5 times more reflux events than controls. Senior et al. [27] showed a decrease in the respiratory disturbance index from 62 to 46 in OSAS patients with GERD who were given antireflux therapy. A cause-effect relationship between GERD and OSAS remains unproven. Whether EER occurs and actually causes irritation of the laryngeal and pharyngeal mucosa, leading to airway obstruction or not, is unknown. It is recognized that apnea episodes are accompanied by negative intrathoracic pressure, which might cause gastric fluid to be sucked into the esophagus and be detected as GERD. Thus, GERD in OSAS patients could be either the cause or the result of apnea events.

\section{EER, Globus Sensation and Dysphagia}

Globus pharyngeus is a common symptom in otolaryngological patients in whom a morphological correlate cannot be seen. As a result, this condition was even formerly labeled as globus hystericus. Nowadays, it is widely believed that GERD and EER are able to induce globus pharyngeus (summarized in Koufman [28]). Woo et al. [29] reported that two thirds of patients with globus had GERD (detected by esophageal $\mathrm{pH}$ monitoring), and other authors describe an incidence between 10 and 90\%. We have recorded EER among $75 \%$ of patients with globus, detected by double-probe 24-hour $\mathrm{pH}$ testing. However, it remains unclear whether globus symptoms result from esophagitis, esophageal dysmotility or from irritation of the pharyngeal mucosa after peptic injury. Reflux disease should be considered in the differential diagnosis of every patient with globus sensation.

The same mechanisms that might be responsible for globus may cause dysphagia, namely chronic irritation of the pharyngeal mucosa, esophagitis or dysmotility of the 
esophagus. The percentage of patients with GERD suffering from dysphagia is estimated to be between 25 and $50 \%$ [28]. Unfortunately, studies using double-probe $\mathrm{pH}$ monitoring are lacking.

\section{Additional Head and Neck Manifestations of EER}

Recent studies have considered a possible association between EER and chronic sinusitis as well as chronic recurrent otitis media. Poelmans et al. [30] described the course of 21 adult patients with middle ear complaints (chronic serous otitis media and feeling of pressure in the ear). Of these, $17(80 \%)$ showed evidence of GERD (esophageal 24-hour $\mathrm{pH}$ monitoring), and all patients responded very well to PPI therapy. It is difficult to imagine that there is direct contact of refluxate with the middle ear mucosa. Fluid would have to pass from the stomach through the esophagus, pharynx, nasopharynx, and eustachian tube to enter the middle ear. Surprisingly, Tasker et al. [31] identified pepsin and pepsinogen in $84 \%$ of middle ear effusions $(n=54)$, suggesting that this pathway actually exists. Regardless, the eustachian tube itself is very sensitive to peptic injury. Animal studies have shown that the exposure of both the nasopharyngeal and the middle ear mucosa results in eustachian tube dysfunction which predisposes to middle ear complaints [32]. Alternatively, a neurogenic influence mediated through vagal stimulation in the esophagus must be considered. These same theories may also apply to chronic sinusitis. Bothwell et al. [33] showed that $75 \%$ of children with chronic sinusitis had abnormal $\mathrm{pH}$ testing, and in $25 / 28$ children sinus symptoms improved with medical antireflux treatment. Similar results have been found in adults [3436].

\section{Host Barriers to Reflux and Treatment}

The two most significant barriers against reflux are the LES and UES. Hiatal herniation allows the barrier of the LES to be easily overcome, increasing susceptibility to GERD. During coughing, the tone of the LES can be overcome by increased intra-abdominal pressure. Furthermore, normal esophageal function, namely coordinated motility, is necessary to ensure esophageal clearance, which in case of a reflux event means immediate clearance from the esophagus towards the stomach. Esophageal clearance time is increased in patients with GERD [4].
Saliva performs a buffering function and acts as a neutralizing agent against gastric acid. Vagally mediated protective reflexes also play an important role. One of these reflexes is the so-called pharyngo-UES contractile reflex. This reflex is stimulated by acid entering the pharynx; the reflex is less sensitive in patients suffering from EER [4]. The epithelium itself is also an effective barrier against gastric contents. The intrinsic mucosal resistance differs between different levels of the upper aerodigestive tract. Thus, the susceptibility to peptic injury differs between the esophagus and other organs, including the larynx. Furthermore, the ability of different mucosal sites to recover from peptic injury may differ [28]. Because of this difference, reflux might be harmless to the esophageal mucosa while causing pathology in mucosa at other levels.

Treatment options for reflux disease include lifestyle changes, pharmacological therapy and surgery. Patients should avoid fatty foods, chocolate, mints as well as caffeine, nicotine, alcohol and carbonated drinks, since these substances tend to increase acid production and can reduce LES tone. Furthermore, patients should avoid any food intake $3 \mathrm{~h}$ prior to bedtime. In obese patients, weight reduction is useful to reduce intra-abdominal pressure. Several drugs are known to have the potential to decrease LES tone, including theophylline, nitrates, diazepam and dopamine. Elevation of the head of the bed is a useful maneuver to decrease intra-abdominal pressure.

Optimal pharmacological therapy includes the use of PPIs. PPIs are able to alter the $\mathrm{pH}$ in the stomach to levels above pH 5 where even pepsin is inactive [4]. In contrast to other antireflux drugs, such as histamine receptor $\left(\mathrm{H}_{2}\right)$ blocking agents or liquid antacids, PPIs must be taken 30-60 min before meals. In an empiric study, it was shown that $67 \%$ of patients with EER improved on an 8week treatment program with the PPI omeprazole $(2 \times$ $20 \mathrm{mg}$ ) [4]. A dose of $20 \mathrm{mg}$ omeprazole daily for 2 weeks, the so-called PPI test used in patients with GERD, seems to be inadequate for the treatment of EER symptoms. The need for more aggressive PPI therapy in EER was reported in a consensus conference report on laryngopharyngeal reflux in 1996 [37]. In addition to PPIs, it is sometimes necessary to supplement with histamine receptor $\left(\mathrm{H}_{2}\right)$ blocking agents (e.g. ranitidine) to overcome the so-called nocturnal acid breakthrough [4]. This phenomenon is well known in GERD patients and pertains to a decrease in the gastric $\mathrm{pH}$ to levels $<4$ at night despite therapy with a PPI. Nocturnal acid breakthrough can be seen in up to $75 \%$ of patients [38]. An alternative to the long-term use of drugs is surgical fundoplication and semifundoplication, with reconstruction of the LES. 


\section{Conclusion}

EER and GERD correlate with numerous diseases and symptoms of the upper aerodigestive tract that are diagnosed and treated frequently by otorhinolaryngologists. Therefore, EER and GERD should be part of the otorhinolaryngologist's diagnostic spectrum. However, a differentiation between EER and GERD is necessary since there are major differences in the clinical presentation of each. Twenty-four-hour double-probe $\mathrm{pH}$ monitoring is the gold standard for diagnosing EER and GERD. Just as the clinical symptoms of GERD and EER differ from one another, optimal treatment differs. Compared to GERD, EER must be treated longer and with higher doses of PPIs to be adequately controlled. Many questions concerning the pathologic mechanisms of diseases due to GERD and EER remain unanswered, but the high incidence of these complaints and the recognition of the negative impact of gastric contents far beyond the stomach has stimulated intense research in this important field, whose improved understanding is sure to be forthcoming.

\section{References}

1 Shaw GY: Application of ambulatory 24-hour multiprobe $\mathrm{pH}$ monitoring in the presence of extraesophageal manifestations of gastroesophageal reflux. Ann Otol Rhinol Laryngol Suppl 2000;184:15-17.

$\checkmark 2$ Koufman JA, Belafsky PC, Bach KK, Daniel E, Postma GN: Prevalence of esophagitis in patients with $\mathrm{pH}$-documented laryngopharyngeal reflux. Laryngoscope 2002;112:16061609.

-3 Noordzij JP, Khidr A, Desper E, Meek RB, Reibel JF, Levine PA: Correlation of $\mathrm{pH}$ probemeasured laryngopharyngeal reflux with symptoms and signs of reflux laryngitis. Laryngoscope 2002; 112:2192-2195.

$\checkmark 4$ Powitzky E: Extraesophageal reflux: The role in laryngeal disease. Curr Opin Otolaryngol Head Neck Surg 2002;10:485-491.

$\checkmark 5$ Postma GN: Ambulatory $\mathrm{pH}$ monitoring methodology. Ann Otol Rhinol Laryngol Suppl 2000; 184:10-14.

-6 Little JP, Matthews BL, Glock MS, Koufman JA, Reboussin DM, Loughlin CJ, McGuirt WF Jr: Extraesophageal pediatric reflux: 24-hour double-probe $\mathrm{pH}$ monitoring of 222 children. Ann Otol Rhinol Laryngol Suppl 1997;169: $1-16$.

7 Yellon RF, Goldberg H: Update on gastroesophageal reflux disease in pediatric airway disorders. Am J Med 2001; 111 (suppl 8A):78S$84 \mathrm{~S}$.

-8 Johnson LF, Demeester TR: Twenty-fourhour $\mathrm{pH}$ monitoring of the distal esophagus. A quantitative measure of gastroesophageal reflux. Am J Gastroenterol 1974;62:325-332.

-9 Smit CF, Tan J, Devriese PP, Mathus-Vliegen LM, Brandsen M, Schouwenburg PF: Ambulatory $\mathrm{pH}$ measurements at the upper esophageal sphincter. Laryngoscope 1998;108:299-302.

-10 Vincent DAJ, Garrett JD, Radionoff SL, Reussner LA, Stasney CR: The proximal probe in esophageal $\mathrm{pH}$ monitoring: Development of a normative database. J Voice 2000;14:247254 .
11 Zalesska-Krecicka M, Krecicki T, Iwanczak B, Blitek A, Horobiowska M: Laryngeal manifestations of gastroesophageal reflux disease in children. Acta Otolaryngol 2002;122:306310 .

12 Ulualp SO, Toohill RJ, Hoffmann R, Shaker $\mathrm{R}$ : Pharyngeal $\mathrm{pH}$ monitoring in patients with posterior laryngitis. Otolaryngol Head Neck Surg 1999;120:672-677.

13 Ylitalo R, Lindestad PA, Ramel S: Symptoms, laryngeal findings, and 24-hour $\mathrm{pH}$ monitoring in patients with suspected gastroesophagopharyngeal reflux. Laryngoscope 2001;111: 1735-1741.

14 Bouchard S, Lallier M, Yazbeck S, Bensoussan A: The otolaryngologic manifestations of gastroesophageal reflux: When is a $\mathrm{pH}$ study indicated? J Pediatr Surg 1999;34:1053-1056.

15 Hickson C, Simpson CB, Falcon R: Laryngeal pseudosulcus as a predictor of laryngopharyngeal reflux. Laryngoscope 2001;111:17421745 .

16 Kuhn J, Toohill RJ, Ulualp SO, Kulpa J, Hofmann C, Arndorfer R, Shaker R: Pharyngeal acid reflux events in patients with vocal cord nodules. Laryngoscope 1998;108:1146-1149.

$>17$ Glanz H, Kleinsasser O: Chronic laryngitis and carcinoma (author's transl). Arch Otorhinolaryngol 1976;212:57-75

18 Galli J, Cammarota G, Calo L, Agostino S, D'Ugo D, Cianci R, Almadori G: The role of acid and alkaline reflux in laryngeal squamous cell carcinoma. Laryngoscope 2002;112:18611865 .

19 El-Serag HB, Hepworth EJ, Lee P, Sonnenberg A: Gastroesophageal reflux disease is a risk factor for laryngeal and pharyngeal cancer. Am J Gastroenterol 2001;96:2013-2018.

20 Koufman JA, Burke AJ: The etiology and pathogenesis of laryngeal carcinoma. Otolaryngol Clin North Am 1997;30:1-19.

21 Loughlin CJ, Koufman JA: Paroxysmal laryngospasm secondary to gastroesophageal reflux. Laryngoscope 1996;106:1502-1505.
22 Maceri DR, Zim S: Laryngospasm: An atypical manifestation of severe gastroesophageal reflux disease (GERD). Laryngoscope 2001;111: 1976-1979.

23 Ludviksdottir D, Bjornsson E, Janson C, Boman G: Habitual coughing and its associations with asthma, anxiety, and gastroesophageal reflux. Chest 1996;109:1262-1268.

24 Harding SM, Richter JE, Guzzo MR, Schan CA, Alexander RW, Bradley LA: Asthma and gastroesophageal reflux: Acid suppressive therapy improves asthma outcome. Am J Med 1996;100:395-405.

-25 Valipour A, Makker HK, Hardy R, Emegbo S, Toma T, Spiro SG: Symptomatic gastroesophageal reflux in subjects with a breathing sleep disorder. Chest 2002;121:1748-1753.

26 Ing AJ, Ngu MC, Breslin AB: Obstructive sleep apnea and gastroesophageal reflux. Am J Med 2000;108(suppl 4a):120S-125S

-27 Senior BA, Khan M, Schwimmer C, Rosenthal L, Benninger M: Gastroesophageal reflux and obstructive sleep apnea. Laryngoscope 2001; 111:2144-2146.

28 Koufman JA: The otolaryngologic manifestations of gastroesophageal reflux disease (GERD): A clinical investigation of 225 patients using ambulatory 24-hour $\mathrm{pH}$ monitoring and an experimental investigation of the role of acid and pepsin in the development of laryngeal injury. Laryngoscope 1991;101(4 Pt 2 Suppl 53):1-78.

29 Woo P, Noordzij P, Ross JA: Association of esophageal reflux and globus symptom: Comparison of laryngoscopy and 24-hour pH manometry. Otolaryngol Head Neck Surg 1996; 115:502-507.

30 Poelmans J, Tack J, Feenstra L: Prospective study on the incidence of chronic ear complaints related to gastroesophageal reflux and on the outcome of antireflux therapy. Ann Otol Rhinol Laryngol 2002;111:933-938.

31 Tasker A, Dettmar PW, Panetti M, Koufman JA, Birchall JP, Pearson JP: Reflux of gastric juice and glue ear in children. Lancet 2002; 359:493. 
>32 White DR, Heavner SB, Hardy SM, Prazma J: Gastroesophageal reflux and eustachian tube dysfunction in an animal model. Laryngoscope 2002;112:955-961.

-33 Bothwell MR, Parsons DS, Talbot A, Barbero GJ, Wilder B: Outcome of reflux therapy on pediatric chronic sinusitis. Otolaryngol Head Neck Surg 1999;121:255-262.
34 Chambers DW, Davis WE, Cook PR, Nishioka GJ, Rudman DT: Long-term outcome analysis of functional endoscopic sinus surgery: Correlation of symptoms with endoscopic examination findings and potential prognostic variables. Laryngoscope 1997; 107:504-510.

35 DiBaise JK, Olusola BF, Huerter JV, Quigley EM: Role of GERD in chronic resistant sinusitis: A prospective, open label, pilot trial. Am J Gastroenterol 2002;97:843-850.
36 Ulualp SO, Toohill RJ, Hoffmann R, Shaker $\mathrm{R}$ : Possible relationship of gastroesophagopharyngeal acid reflux with pathogenesis of chronic sinusitis. Am J Rhinol 1999;13:197-202.

37 Koufman J, Sataloff RT, Toohill R: Laryngopharyngeal reflux: Consensus conference report. J Voice 1996;10:215-216.

38 Peghini PL, Katz PO, Bracy NA, Castell DO: Nocturnal recovery of gastric acid secretion with twice-daily dosing of proton pump inhibitors. Am J Gastroenterol 1998;93:763-767. 